\title{
Resenha sobre o livro O Método Apoio como Ferramenta de Prevenção e Enfrentamento da Judicialização da Saúde no SUS
}

\author{
Review of the book O Método Apoio como Ferramenta de Prevenção \\ e Enfrentamento da Judicialização da Saúde no SUS
}

\author{
Reseña del libro O Método Apoio como Ferramenta de Prevenção e \\ Enfrentamento da Judicialização da Saúde no SUS
}

\begin{abstract}
O MÉTODO APOIO COMO FERRAMENTA DE PREVENÇÃO E ENFRENTAMENTO DA JUDICIALIZAÇÃO DA SAÚDE NO SUS. Amaral TC. São Paulo: Hucitec Editora; 2020. 146 p. ISBN: 97865-86039-39-9.
\end{abstract}

doi: 10.1590/0102-311X00099821

Com a ampliação do direito à saúde no Brasil desde a Carta Constitucional de 1989, diversos desafios vêm se manifestando no sentido da concretização de um sistema público de saúde universal e gratuito, em conjunturas políticas, sociais e econômicas diversas e, por muitas vezes, contraditórias. Nessa perspectiva, a judicialização da saúde inicia enquanto um fenômeno no país na década de 1990 em “... um cenário político neoliberal e com as demandas de saúde em crescimento e sob a responsabilidade de um sistema universal subfinanciado que passou a ter de racionalizar recursos..." 1 (p. 34).

Do ponto de vista das estratégias que emergiram ao longo dos anos na busca pela atenção integral e resolutiva à saúde no país, a clínica ampliada ganha visibilidade, principalmente a partir da publicação da Política Nacional de $\mathrm{Hu}$ manização, que traz a possibilidade de um manejo mais eficaz da complexidade do trabalho em saúde 2 . Assim, a clínica ampliada põe, em questão, a fragmentação dos sujeitos, propondo uma abordagem interdisciplinar que dê conta de uma compreensão mais alargada do processo saúde-doença.

Nesse contexto, a concepção teórica e metodológica Paideia, desenvolvida por Gastão Wagner de Sousa Campos 3, configura-se como um caminho para pensar a cogestão de coletivos e vem sendo amplamente utilizada em políticas e práticas de saúde no Brasil, tendo como eixos de atuação: Apoio Institucional, Apoio Matricial e Clínica Ampliada e Compartilhada 4. A presente obra aponta a possibilidade da aplicação desse método vinculado ao cuidado das pessoas que buscam soluções jurídicas para seus problemas de saúde, reconhecendo, nesse coletivo, a diversidade de saberes dos atores envolvidos 1 .

O livro conta com um prefácio auspicioso de Gastão Wagner de Sousa Campos que traduz o sentimento de esperança na possibilidade de encontrar caminhos que levam a melhores resultados na busca, não só pela prevenção, mas também pelo enfrentamento das iniquidades em saúde. Sentimento esse que nitidamente parece inspirar a autora e, consequentemente, os leitores ao longo de toda a obra.

O capítulo 1 detalha, com clareza, a metodologia utilizada na construção da pesquisa que origina o livro, localizando o leitor quanto à judicialização da saúde em Jundiaí, São Paulo - cenário onde se desenvolve o estudo apresentado e salientando a imprescindibilidade do olhar para a gestão municipal do Sistema Único de Saúde (SUS) no contexto do fenômeno em tela. 
O capítulo 2 propicia ao leitor uma imersão no cenário mais macro da judicialização da saúde no território nacional, e em outros países na perspectiva de sistemas universais de saúde, incluindo a bioética como um importante eixo de análise, e que, no caso do Brasil, envolve ainda, paralelamente, a dimensão do sistema privado. Pauta-se ainda, nesse capítulo, a discussão sobre a racionalidade da tomada de decisões pelo judiciário no campo da saúde no Brasil, sendo esse um elemento de debate extremamente atual que urge o esforço de pesquisadores que possam enfocar o Estado como objeto de análise para melhor compreendermos as relações e imbricações entre os três poderes e os impactos dessas relações nas esferas de gestão estadual e municipal, sob a ótica do federalismo brasileiro.

No capítulo 3, a escrita de leitura leve e envolvente da experiência da autora disseca o percurso metodológico percorrido para o alcance do desenvolvimento do Guia de Apoio à Prevenção e Enfrentamento da Judicialização no SUS, resultado esse que conforma o cerne da obra e é apresentado, na íntegra, ao fim desse capítulo.

Ressalta-se a intencionalidade do desenho da metodologia de apoio "para propositura de ações preventivas e de enfrentamento da Judicialização da saúde promovida contra os municípios" 1 (p. 54). Nesse sentido, o leitor é levado a uma imersão nas estratégias experenciadas pela autora, cujas vivências parecem encorajar-nos a cada página, ao vislumbre de novas possibilidades de manejo das questões referentes à judicialização da saúde, a partir do reconhecimento da potência de um trabalho coletivo efetivamente interdisciplinar e interprofissional. Tendo em vista a complexidade do fenômeno em questão, defende-se ser essencial a compreensão de que "a efetivação da saúde pode passar também pela incorporação das instituições jurídicas no cotidiano da gestão" 5 (p. 46). E a presente obra traduz, em certo aspecto, essa possibilidade de forma bastante concreta.

O capítulo 4 apresenta os olhares dos especialistas acerca do Método Apoio, deixando cada vez mais clara a ideia de que, em muitos aspectos, esse método vai além de uma proposta de mediação sanitária. A validação das estratégias identificadas a partir da experiência abordada permitiu a produção de espaços coletivos que promovam a discussão da judicialização da saúde além de viabilizar o conhecimento das dimensões éticas, políticas, econômicas e jurídicas do fenômeno em Jundiaí.

O capítulo 5 aborda os resultados quantitativos obtidos na pesquisa, trazendo um panorama do perfil da judicialização da saúde, incluindo dados mais detalhados a partir da implementação das estratégias indicadas no estudo, que permitiu uma análise mais pormenorizada a partir de 2015.

O capítulo 6 encerra o livro pontuando a importância dos "encontros no campo do saber e do fazer", conforme enunciado no próprio título do capítulo. Explicita a importância das reorganizações de processos de trabalho, da agregação da diversidade de saberes, do reconhecimento dos limites das estratégias, dentre outros aspectos que corroboram para um fechamento da obra que, na verdade, propicia a abertura de múltiplas possibilidades. Possibilidades essas encorajadoras que fazem do livro uma inspiração para aqueles que desejam enfrentar a questão da judicialização da saúde pelo viés da democratização institucional e da busca por práticas dialógicas, interdisciplinares e interprofissionais.

Ainda que não seja esse o debate central da obra, percebe-se fortemente a tecitura de saídas possíveis para se lidar com o paradigma do direito individual versus o direito coletivo à saúde, de modo a mitigar os impactos que esse imbróglio acaba por imprimir nas práticas da judicialização da saúde no nível da gestão municipal do SUS. Nesse sentido, Bisol \& Rey Filho 6 (p. 9) defendem que "não é admissível que o exercício individual de um direito social sanitário desconfigure e torne inviável a sua própria efetividade político-administrativa, ou seja, a maximização da capacidade de oferta das ações e serviços de saúde”. Nesse aspecto, a experiência compartilhada pela autora aponta para novas formas de acolher a singularidade do indivíduo que demanda sem perder o olhar para as ferramentas da saúde baseadas em evidências e para as possibilidades que estão dadas nos fluxos instituídos da própria rede de atenção à saúde, de modo a otimizar os recursos existentes.

Tendo em vista que o método Paideia busca: o favorecimento da democratização da gestão nas organizações, a ampliação da capacidade das pessoas para lidar com conflitos, manejar e interpretar informações, num processo de compreen- 
são de si mesmas, dos outros e do contexto ${ }^{4}$, a presente obra, sem dúvida, marca um importante avanço no campo das possibilidades existentes nos processos de trabalho atrelados ao fenômeno da judicialização da saúde no Brasil, uma vez que o manejo adequado desse mobiliza necessariamente o que se perscruta o método.

Dessa forma, a experiência retratada presenteia os leitores com elementos que, aliados ao reconhecimento da importância da avaliação de tecnologias em saúde, da fundamentalidade do apoio institucional e da consolidação de espaços de diálogos que permitam o desenvolvimento de práticas produtoras de saúde a partir da clínica ampliada e compartilhada, refletem o comprometimento daqueles que lutam por um SUS mais equitativo e mais potente na perspectiva da efetivação da justiça social, contribuindo substancialmente para o fortalecimento da política pública de saúde concretizada na esfera municipal..

Isabela Tavares Amaral 1

1 Universidade Federal do Rio de Janeiro, Rio de Janeiro, Brasil.

isabela.t.amaral@gmail.com

\section{Informação adicional}

ORCID: Isabela Tavares Amaral (0000-0003-40436020).

1. Amaral TC. O Método Apoio como ferramenta de prevenção e enfrentamento da judicialização da saúde no SUS. São Paulo: Hucitec Editora; 2020.

2. Secretaria de Atenção à Saúde, Ministério da Saúde. Política Nacional de Humanização da Atenção e Gestão do SUS: clínica ampliada e compartilhada. Brasília: Ministério da Saúde; 2009.

3. Campos GWS. Um método para análise e cogestão de coletivos. São Paulo: Hucitec Editora; 2000.

4. Campos GWS, Figueiredo MD, Pereira Júnior N, Castro CP. A aplicação da metodologia Paideia no apoio institucional, no apoio matricial e na clínica ampliada. Interface Comun Saúde Educ 2014; 18 Suppl 1:983-95.

5. Asensi FD, Pinheiro R. Judicialização da saúde no Brasil: dados e experiências. Brasília: Conselho Nacional de Justiça; 2015.

6. Bisol J, Rey Filho MR. Por que uma teoria geral do direito sanitário? In: Alves SMC, Lemos ANLE, organizadores. Direito sanitário: coletânea em homenagem à Prof. ${ }^{a}$ Maria Célia Delduque. São Paulo: Editora Matrioska; 2020. p. 3-20.
Recebido em 19/Abr/2021

Versão final reapresentada em 14/Jun/2021

Aprovado em 22/Jun/2021 